\title{
In-flight angina pectoris; an unusual presentation
}

Firas Al-Janabi ${ }^{12^{*}}$ (D), Regina Mammen ${ }^{3}$, Grigoris Karamasis ${ }^{1,2}$, John Davies ${ }^{1,4}$ and Thomas Keeble T,2,4 $^{1,4}$

\begin{abstract}
Background: An unusual case of typical angina which occurred on a long haul flight is presented. This case is notable as this was the index presentation, with no previous symptoms prior to this. Physiological changes at altitude can be marked, and include hypoxia, tachycardia and an increase in cardiac output. These changes were enough to expose underlying angina in our patient.

Case presentation: A 68 year old man presented with typical cardiac chest pain on a long haul flight. His symptoms first started 10-15 min after take-off and resolved on landing. This was his index presentation, and there were no similar symptoms in the past. Background history included hypercholesterolaemia and benign prostatic hypertrophy only. He led a rather sedentary lifestyle.

A CT coronary angiogram showed significant disease in the proximal left anterior descending artery and proximal right coronary artery. He went on to have a coronary angiogram with invasive physiological measurements, which determined both lesions were physiologically significant. Both arteries were treated with drug eluting stents. Since treatment, he once again embarked on a long haul flight, and was completely asymptomatic.

Conclusion: The presentation of symptoms in this individual was rather unusual, but clearly caused by significant coronary artery disease. Potentially his sedentary lifestyle was not enough in day-to-day activities to promote anginal symptoms. When his cardiovascular system was physiologically stressed during flight, brought about by hypoxia, raised sympathetic tone and increased cardiac output, symptoms emerged. In turn, when landing, with atmospheric conditions normalised, physiological stress was removed, and symptoms resolved. Clinically therefore, one should not exclude symptoms that occur with differing physiological states, such as stress and altitude, as they are also potential triggers for myocardial ischaemia, despite absence of day-to-day symptoms.
\end{abstract}

Keywords: Angina, Flight, Coronary artery disease, Pressure wire, Fractional flow reserve

\section{Background}

The physiological effects of high altitude on the cardiorespiratory system are well-known. Exposure to high altitudes can exacerbate the symptoms of underlying disease, depending on the altitude and length of exposure. Most of the reported in-flight medical emergencies occur in people with pre-existing medical conditions, with exacerbation of respiratory conditions being the commonest complaint, followed by angina [1]. However, occasionally new symptoms arise in otherwise healthy individuals. The commonest medical emergencies

\footnotetext{
* Correspondence: firas.aljanabi@btuh.nhs.uk

${ }^{1}$ Essex Cardiothoracic Centre, Basildon Hospital, Nethermayne, Basildon, Essex SS16 5NL, UK

${ }^{2}$ Anglia Ruskin University, Bishop Hall Lane, Chelmsford, Essex CM1 1SQ, UK Full list of author information is available at the end of the article
}

encountered in-flight are syncope and gastro-intestinal disorders $[1,2]$.

We present the case of a 68 year old gentleman with no significant past medical history who developed new onset of angina whilst on a long haul flight, with symptoms occurring at cruising altitude and resolving on landing. He had no prior symptoms, making his presentation unusual.

\section{Case presentation}

A 68 year old gentleman was referred to the cardiology clinic due to an episode of chest pain which occurred whilst travelling from the UK to Australia via Singapore. He developed chest tightness after take-off in the UK which persisted continuously for the entire duration of the flight until it landed in Singapore on transit. When 
the flight touched down on ground, he noticed that the tightness had completely disappeared. It recurred after take-off and once again, persisted throughout the journey from Singapore to Australia. The pain was cardiac in nature. He has never smoked. A chest x-ray and a CT pulmonary angiogram done previously had not revealed any lung parenchymal disease. His cholesterol levels were 5.3 with raised low density lipoprotein (LDL) of 3 . 5. There was no significant past medical history except for benign prostatic hypertrophy for which he took Finasteride and Tamsulosin. Physical examination was unremarkable.

His resting electrocardiogram (ECG) revealed a normal sinus rhythm with normal cardiac intervals. His clinical examination was normal. Blood pressure in clinic was raised at 165/112 $\mathrm{mmHg}$, however, a subsequent $24 \mathrm{~h}$ blood pressure monitor only revealed a mildly raised mean nocturnal blood pressure of 137/87 $\mathrm{mmHg}$. Initially a CT coronary angiogram was organised due to the unusual presentation. This revealed significant stenoses in the proximal to mid left anterior descending artery (LAD) and the proximal right coronary artery (RCA) with a $50 \%$ stenosis in the circumflex and obtuse marginal artery. An invasive coronary angiogram confirmed critical proximal to mid RCA stenosis (Fig. 1) and a long segment of proximal LAD stenosis (Fig. 2).

Fractional flow reserve (FFR) measurement in the RCA was strongly positive (Fig. 3) and the lesion was subsequently treated with a drug eluting stent. FFR measurement in the LAD was also physiologically positive and in

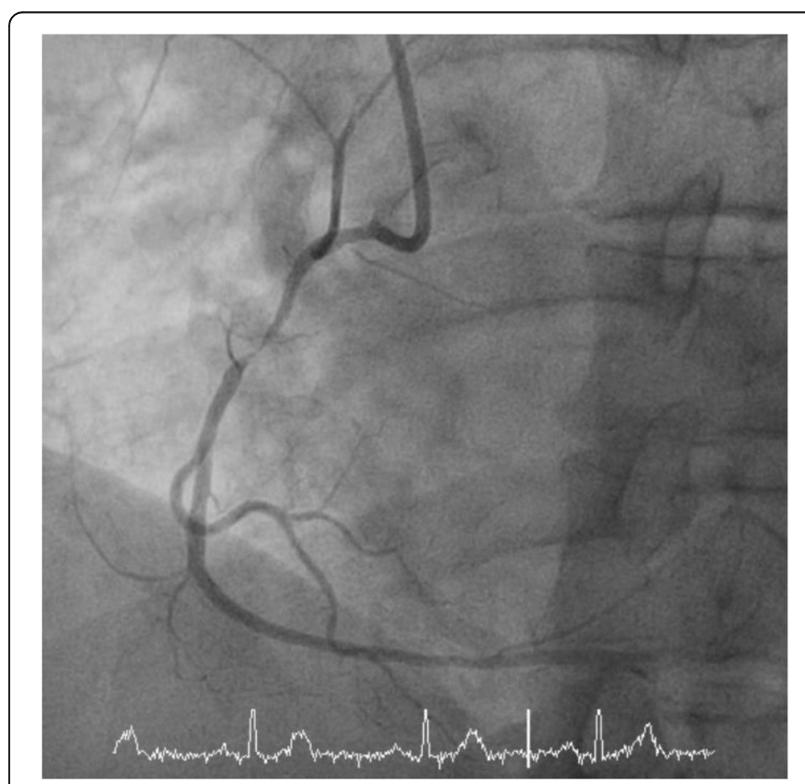

Fig. 1 Invasive angiography demonstrating a severe proximal right coronary artery (RCA) lesion. On invasive physiological assessment, this was deemed a flow limiting stenosis and treated with a drug eluting stent

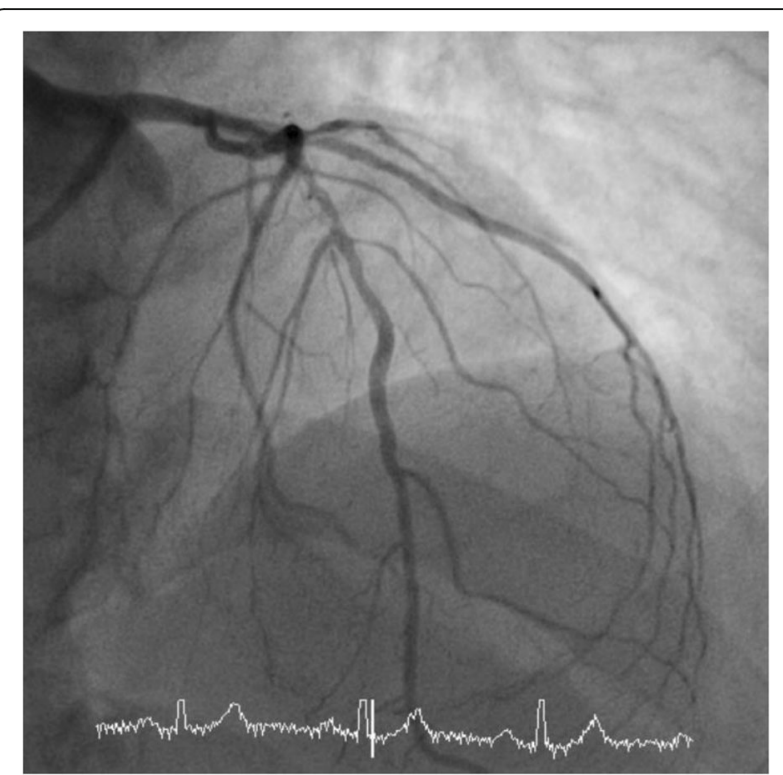

Fig. 2 Invasive angiography demonstrating a long lesion in the proximal left anterior descending artery (LAD). Once again, on invasive physiological assessment, this was deemed flow limiting, and treated with a drug eluting stent

turn this also treated with a single drug eluting stent. Following treatment he flew again with no recurrence of symptoms.

\section{Discussion}

This gentleman had an unusual presenting history. His symptoms were assessed as likely cardiac (but not completely typical) and in the first instance a CT coronary angiogram was conducted. CT scans may over or underestimate findings of coronary artery disease, meaning over, or under diagnosis. This was potentially an area of concern, in that his disease may have been missed. The findings on CT scanning correlated well with angiographic findings in this case. Given the nature of his symptoms, other methods of testing, such as stress echo or CMR, would have been valid alternatives at the time of his presentation. In November 2016, current National Institute of Clinical Excellence (NICE) guidelines on chest pain were reviewed, and coronary CT is now the initial investigation of choice in stable patients with typical or atypical chest pain [3].

\section{Physiological effects of high altitude}

Commercial flights usually fly at an altitude of 25,000 to $35,000 \mathrm{ft}$. However, flight cabins are pressurised to an equivalent altitude of $5000-8000 \mathrm{ft}$., which equates to an inspired oxygen fraction of $0.17-0.15$ at sea level [4]. Alveolar oxygen tension is known to decrease to $65 \mathrm{mmHg}$ at $8000 \mathrm{ft}$., with a resultant reduction in arterial oxygen tension to $60 \mathrm{mmHg}$ in healthy individuals [5]. Hypoxaemia augments the sympathetic nervous system and has many 


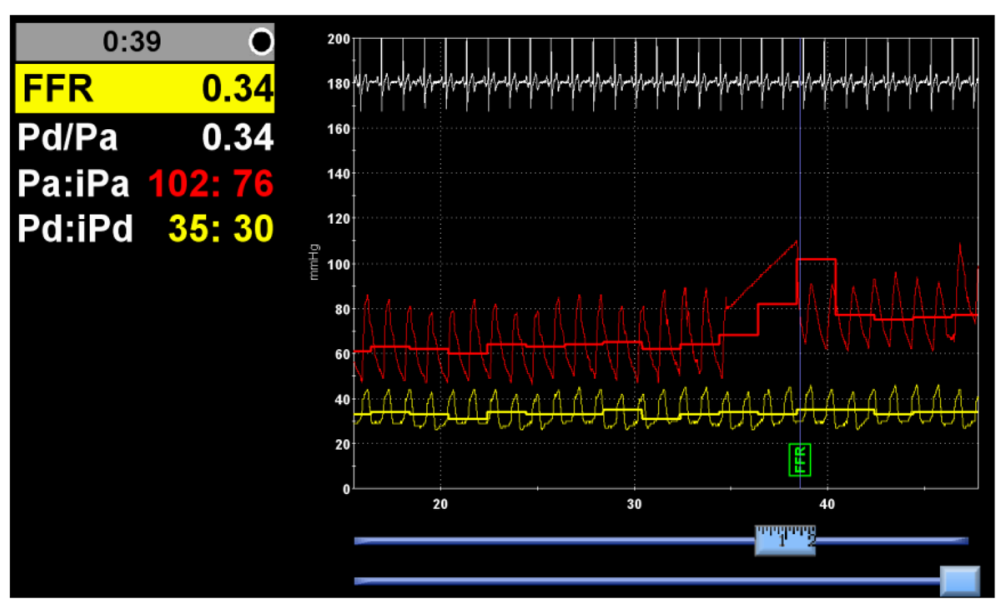

Fig. 3 Fractional Flow Reserve (FFR) measurement of the right coronary artery lesion. A value of 0.34 was obtained, which is grossly below the cut-off value of 0.8

physiological effects. There is an increase in ventilatory effort in response to hypoxic conditions and the cardiovascular system responds by elevation of the heart rate, with subsequent reduction of stroke volume and an increased risk of angina and dysrhythmias in coronary patients [6]. The oxygen dissociation curves in healthy adults show that even at $65 \mathrm{~mm}$. Hg the haemoglobin is still $80 \%$ saturated with oxygen [7]. The healthy adult is therefore hardly affected at the highest altitude that an aircraft cabin may reach in ordinary conditions, but an individual with impairment to the respiratory or cardiovascular system, may be distressed by this degree of hypoxia [8].

In one study, moderate altitude exposure in the elderly was associated with hypoxemia, sympathetic activation, and pulmonary hypertension resulting in a reduced exercise capacity that is predictable based on exercise performance at sea level. Patients with coronary artery disease who are well compensated at sea level do well at moderate altitude, although acute ischemia may be provoked at modestly lower myocardial and systemic work rates [9].

Cardiac output characteristically increases initially with hypoxia in a dose-dependent fashion, primarily due to tachycardia. The cardiac response slowly decreases over time despite continued hypoxia for unclear reasons [10, 11].

In our case described above, there was a critical right coronary artery stenosis, and a long segment of LAD disease, the severity of which was confirmed using fractional flow reserve. After coronary revascularisation, he made another journey from UK to Australia, and his symptoms did not recur. Therefore, we believe that the chest tightness which he had developed in-flight during his index journey was indeed due to cardiac ischaemia. The hypoxia during the flight would have led to an increased sympathetic response which brought on symptoms of ischaemia at rest. It remains unclear why he did not have any anginal symptoms on exertion prior to his flight. He led a rather sedentary lifestyle which may explain his lack of day-to-day symptoms.

\section{Current consensus on fitness to fly}

A working group publication by the British Cardiovascular Society relating to fitness to fly for passengers with cardiovascular disease, was published in 2010 [12]. In patients with CCS class I-II angina, flight was unrestricted. Patients with class III angina are suggested to have airport assistance and in flight oxygen available. Delay of travel is recommended in patients with class IV angina. If there is no alternative to flight, a medical escort and in flight oxygen is advised. In the case of elective PCI with no complications, a rest period of 2 days is suggested.

In patients who have recently suffered an Non-ST segment elevation myocardial infarction (NSTEMI), or ST segment elevation myocardial infarction (STEMI), guidelines are based on age, whether reperfusion was successful, and ejection fraction after the event. Those aged less than 65 was successful reperfusion and an ejection fraction > $45 \%$ are deemed low risk, and can fly after 3 days. An ejection fraction $>40 \%$ with no symptoms of heart failure, and no urgently planned treatment or investigations are deemed medium risk, and are advised it is safe to fly after 10 days. Patients with an ejection $<40 \%$ with symptoms of heart failure and incomplete treatment or investigations are high risk, and advised to defer travel completely.

\section{Conclusion}

This 68 year old gentleman had an index presentation of angina whilst on a commercial flight at cruising altitude. His underlying coronary artery disease was exacerbated by the combination of hypoxia, reflex tachycardia and increase in cardiac output plus paradoxical vasoconstriction [9]. After treatment, his symptoms did not recur on a further commercial flight. 


\section{Abbreviations}

CT: Computerised tomography; ECG: Electrocardiogram; FFR: Fractional flow reserve; LAD: Left anterior descending artery; LDL: Low density lipoprotein; NSTEMI: Non-ST segment elevation myocardial infarction; RCA: Right coronary artery; STEMI: ST segment elevation myocardial infarction

\section{Acknowledgements}

Nil

\section{Funding}

No funding obtained for production of this case report.

\section{Availability of data and materials}

The data and medical records of the case outlined are held securely, as outlined by the data protection act, on hospital systems. Relevant anonymised data regarding this case have been added as figures where appropriate.

\section{Authors' contributions}

FA and RM were the major contributors to background research and production of the case report. GK, JD and TK revised and contributed to the production of initial and final manuscript drafts as well as reviewing the final manuscript critically for intellectual content. All authors read and approved the final manuscript.

\section{Ethics approval and consent to participate}

Procedures conducted were part of standard medical practice, and hence no formal ethical approval was sought.

\section{Consent for publication}

Full consent was obtained in written form from the patient for publication of relevant data, images, and medical history.

\section{Competing interests}

The authors declare that they have no competing interests.

\section{Publisher's Note}

Springer Nature remains neutral with regard to jurisdictional claims in published maps and institutional affiliations.

\section{Author details}

${ }^{1}$ Essex Cardiothoracic Centre, Basildon Hospital, Nethermayne, Basildon, Essex SS16 5NL, UK. ${ }^{2}$ Anglia Ruskin University, Bishop Hall Lane, Chelmsford, Essex CM1 1SQ, UK. ${ }^{3}$ St Bartholomew's Hospital, W Smithfield, London EC1A 7BE,

UK. ${ }^{4}$ Southend General Hospital, Prittlewell Chase, Westcliff-on-Sea SSO ORY, UK.

\section{Received: 30 October 2017 Accepted: 25 March 2018}

Published online: 05 April 2018

\section{References}

1. Quershi A. Emergencies in the air. Emerg Med J. 2005;22:658-9.

2. Sand M. Surgical and medical emergencies on board European aircraft: a retrospective study of 10189 cases. Crit Care. 2009;13:R3.

3. Chest pain of recent onset: assessment and diagnosis. (NICE Guideline CG95). National Institute for Health and Care Excellence (2010, Updated 2016). https://www.nice.org.uk/guidance/cg95. Accessed 20 Jan 2018.

4. Cramer D. Assessment of oxygen supplementation during air travel. Thorax. 1996;51:202-3

5. Cottrell JJ. Altitude exposures during aircraft flight: flying higher. Chest. 1992;92:81-4

6. Peacock AJ. ABC of oxygen: oxygen at high altitude. Br Med J. 1998:317: 1063-5.

7. Korner PI. Circulatory adaptations to hypoxia. Physiol Rev. 1959;39:687-730.

8. Beighton PH. Cardiovascular disease in air travellers. Brit Heart K. 1968;30:367.

9. Levine BD. Effect of high-altitude exposure in the elderly. Circulation. 1997; 96:1224-32.

10. Phillips BA. The effects of hypoxemia on cardiac output: a dose-response curve. Chest. 1988:93:471

11. Levine BD. Going high with heart disease: the effect of high altitude exposure in older individuals and patients with coronary artery disease. High Alt Med Biol. 2015;16(2):89-96.

12. Smith D. Fitness to fly for passengers with cardiovascular disease. Heart. 2010;96(Suppl 2):ii1-16.

\section{Submit your next manuscript to BioMed Central and we will help you at every step:}

- We accept pre-submission inquiries

- Our selector tool helps you to find the most relevant journal

- We provide round the clock customer support

- Convenient online submission

- Thorough peer review

- Inclusion in PubMed and all major indexing services

- Maximum visibility for your research

Submit your manuscript at www.biomedcentral.com/submit
) Biomed Central 